\title{
Editorial
}

\section{Welcome to Religions, a New Open Access, Multidisciplinary and Comprehensive Online Journal}

\section{Peter Iver Kaufman ${ }^{1,2}$}

1 Emeritus Professor, Departments of Religious Studies and History, University of North Carolina, CB 3225-UNC-CH, Saunders Hall, Chapel Hill, NC 27599, USA

2 George Matthews and Virginia Brinkley Modlin Professor of Leadership Studies, Jepson School, University of Richmond; 28 Westhampton Way, VA 23173, USA;

E-Mail: pkaufman@ richmond.edu; Tel.: +1-804-289-8003

Received: 7 June 2010 / Accepted: 8 June 2010 / Published: 10 June 2010

We always seem to be in the wake of some current event or controversy that reminds us just how important scholarly interest in religions has been, is, and will be. Fortunately, new sources for religious movements - even sources that illumine those movements' origins-keep turning up, and many sources, long considered critical, are now accessible online. Furthermore, fresh developments in the disciplines that consistently make significant contributions to our understanding of religious personality, authority, devotion, and community—disciplines ranging from psychology, sociology, and anthropology to history, art history, philosophy, literary criticism, and political science-fuel general, as well as scholarly, interest in the world's religions. Without exaggeration, one can claim we have an embarrassment of riches. Consequently, the study of religious crises, commitments, and critics of the latter has never been livelier.

Literature, of course, responds to life, in this instance. Other journals, the elder and well-established siblings of Religions, make strenuous and altogether admirable efforts to keep readers alert to many revisionist interpretations and exciting advances in certain areas of the field, and a few comprehensive journals continue to earn our appreciation for inviting innovative, often comparative, contributions. The advantages of such comprehensive journals for specialists in one or another field of religious studies are not always obvious. Some colleagues not only learn of the latest in fields familiar to them, but also discover intriguing new approaches to religious artifacts and experiences by browsing the recent acquisitions in their libraries. These scholars will attest to the value of the places online, or in bookstalls, that trigger our curiosity and encourage us to contemplate our methods and mission.

Religions intends to address some of the problems occasioned by the abundant literature, notably, the deplorably long stretch between submission and publication. The managing editors and 
accomplished, versatile editorial board are dedicated, not simply to publishing papers and conference proceedings of conspicuous quality, but also to providing prompt, as well as expert counsel. Ordinarily, submissions will be refereed within a month of their arrival. Publication, when recommended, should follow expeditiously. Our new enterprise welcomes your interest, naturally, but also your suggestions for special issues, your contributions, and your advocacy. On that last count, consider Religions when several papers in a conference session you have organized or attended would be all the more revealing if published together, and promptly. Consider Religions if-your investigation or dissertation done-your opportunities to locate what you've learned in other venues will involve extensive costs or delays, or both. Consider Religions should you think that one or more recent publications ought to be appreciatively and critically_carefully but quickly_reviewed. Finally, consider Religions as a new, exceptional, exciting enterprise ready to reward your trust, attention, and participation.

(C) 2010 by the authors; licensee MDPI, Basel, Switzerland. This article is an Open Access article distributed under the terms and conditions of the Creative Commons Attribution license (http://creativecommons.org/licenses/by/3.0/). 